\title{
Editorial
}

\section{Vitamin D research and public health nutrition: a current perspective}

This 2017 special issue of Public Health Nutrition features nineteen research manuscripts all relevant to the role of vitamin D nutritional status in the risk and prevention of chronic diseases of public health importance. A useful barometer gauging the worldwide growing interest in vitamin D and health research is shown by over 13000 studies abstracted in PubMed over the last 5 years alone, all with a focus on vitamin D. Vitamin D deficiency in Europe is associated with adverse health outcomes whose direct and indirect medical cost burdens have been estimated in the hundreds of billions of Euros, which underlines the importance of this work to public health ${ }^{(1)}$. Dedicating a special issue to these recently accepted vitamin D studies provides Public Health Nutrition editors with an opportunity to set in perspective the diverse aspects of the continued growing interest in vitamin D nutritional status, its health importance, and the impact of the many recent innovations in analytical methods, assay standardization programmes and the underlying factors contributing to the controversy over serum cut-off values defining vitamin D nutritional status. Newer standardized analytical methods now enable research exploring the many gaps in our understanding of vitamin D nutritional status which many of these papers address, as well as the association with reduced risk of disease and other beneficial health effects.

The common feature among all the papers in this special vitamin $\mathrm{D}$ issue is the measurement of vitamin $\mathrm{D}$ status or the circulating concentrations of 25-hydroxyvitamin D (25 $(\mathrm{OH}) \mathrm{D}, \mathrm{nmol} / \mathrm{l}$ or $\mathrm{ng} / \mathrm{ml})$. There is a growing demand to assess vitamin D status in order to screen for deficiency, monitor efficacy of supplementation or fortification, or assess the association between vitamin D status and chronic diseases including osteoporosis, diabetes, cancer, CVD, infection and autoimmune or neurological disorders. To meet this demand, less labour-intense assay methods have been developed along with certified external standards and proposed criteria for defining vitamin D deficiency/sufficiency ${ }^{(2-5)}$.

The goal of this perspective is to inform researchers about the currently accepted assay methods and quality control procedures used to determine $25(\mathrm{OH}) \mathrm{D}$ concentrations and the most widely accepted criteria for establishing vitamin D status. We present some background information describing relevant new evidence in four areas defining important public health gaps in knowledge that are addressed by many of the studies in this issue. Our intent is to provide insight into how these studies contribute to these gaps in our understanding of vitamin D status and, more importantly, how the study findings may impact public health nutrition policy and practices.

\section{Gaps in vitamin D understanding relevant to public health}

The four areas addressing critical gaps in our knowledge of vitamin D status and health that were tackled by the studies in this special issue include: (i) global vitamin D deficiency and association with health risk; (ii) impact of or need for national vitamin $\mathrm{D}$ food fortification; (iii) vitamin D supplement use in vulnerable populations; and (iv) season and sunlight influence year-round. Among these areas, global vitamin D deficiency and association with health risk was the most repeated manuscript focus and is clearly the most controversial. Recent evidence supports global vitamin $\mathrm{D}$ deficiency $^{(6,7)}$ and numerous systematic reviews and meta-analyses examining multiple health outcomes and mortality risk $^{(8-11)}$ show association with vitamin D deficiency, notably when individual participant data are used in the meta-analyses ${ }^{(11)}$. However, these findings are largely based on data from European and higher-income countries, underscoring the need for and importance of diverse geographic studies such as the ones presented in this issue.

Evidence of global vitamin D deficiency and its association with adverse health speaks to the need for national food fortification programmes, both in Europe and lower- and middle-income countries ${ }^{(12,13)}$. Fortification of food is the most effective population-based approach to correcting poor vitamin D status $^{(13)}$, while supplementation of specific groups at high risk within a population is a targeted intervention to rapidly correct serious deficiencies. Even in countries with year-round abundant sunshine for endogenous skin synthesis of vitamin $\mathrm{D}$, recent findings show there is a need for national food fortification programmes in order to reach the entire population, again stressing the necessity for worldwide studies $^{(14)}$. Vitamin D supplement use faces many barriers as a population strategy to prevent vitamin D deficiency and adverse health outcomes ${ }^{(15)}$, although supplementation may prove effective in small groups or individuals at risk ${ }^{(16,17)}$. Nevertheless, caution is warranted for individuals who self-medicate out of necessity in countries where sun is avoided, food is not fortified and vitamin D supplements are not well regulated, such as India ${ }^{(16)}$. More geographically diverse studies are needed exploring the efficacy of vitamin D supplement use in vulnerable populations, especially during 
pregnancy and early infancy. Vitamin D supplement use has been shown to be effective in populations where sun exposure is limited during the winter ${ }^{(17,18)}$. Seasonal changes and sunlight availability alone are unable to explain seasonal differences in countries' population vitamin D status when their populations experience the same limited sunlight. This finding points to the need to assess other contributing sources such as diet and other confounding lifestyle factors when developing strategies to prevent vitamin D deficiency ${ }^{(19)}$.

Knowledge of the effective sunlight (UVB) availability during each season has recently been used to develop an integrated predictive model of serum 25(OH)D concentrations that can be applied to fortification and supplementation strategies to prevent seasonal vitamin D deficiency ${ }^{(20)}$. Such models were used to show similar UVB availability in northern European countries, each of which showed similar decreases with latitude and seasonal changes, but different magnitudes of seasonal fluctuations in serum $25(\mathrm{OH}) \mathrm{D}$ were observed, ostensibly due to differences in the vitamin $\mathrm{D}$ content of the diet ${ }^{(19)}$. Yet again, these findings are based on European data, leaving a gaping hole in our understanding of the interaction between season, environment, cultural lifestyle, dietary sources and vitamin D status in other countries.

\section{Need for global consensus on the definitions of vitamin $D$ nutritional status}

To better understand the global importance of vitamin D deficiency to public health, a consensus must be reached on the definition of what serum concentration of $25(\mathrm{OH}) \mathrm{D}$ to use to define a deficient state. Concentrations ranging from $<25$ to $<75 \mathrm{nmol} / 1$ ( $<10$ to $<30 \mathrm{ng} / \mathrm{ml})$ have been proposed as cut-off measures for deficiency using unstandardized assays reporting great variability in outcomes ${ }^{(21)}$. Race, gender, age, lifestyle, physiological state and disease can impact serum $25(\mathrm{OH}) \mathrm{D}$ concentrations in individuals and populations, thus complicating efforts to reach global consensus on what serum $25(\mathrm{OH}) \mathrm{D}$ concentration constitutes a vitamin D-deficient state ${ }^{(22,23)}$.
There is, however, general agreement in defining the characteristics of a vitamin D-deficient state as it relates to skeletal health that researchers may use to enable global comparisons $^{(7)}$. Established by the Institute of Medicine ${ }^{(22)}$ and shown in Table 1, deficiency represents concentrations not sufficient to provide protection against rickets and osteomalacia (adverse bone events; $<30 \mathrm{nmol} / \mathrm{l}$ or $<12 \mathrm{ng} / \mathrm{ml}$ ); while sufficiency represents concentrations not at risk for adverse bone events $(>50 \mathrm{nmol} / 1 \text { or }>20 \mathrm{ng} / \mathrm{ml})^{(22)}$. The Institute of Medicine report did not define optimal vitamin D status; nevertheless, other scientific experts define serum concentrations exceeding $75 \mathrm{nmol} / \mathrm{l}(30 \mathrm{ng} / \mathrm{ml})$ as optimal, especially for those individuals at greater risk due to disease, race or other factors ${ }^{(22,23)}$. There is growing but inconsistent evidence of associations between chronic disease conditions other than skeletal with serum concentrations below this range ${ }^{(24)}$. More convincing evidence is warranted with respect to cancer risks for which lower risks have recently been reported with higher serum concentrations of $25(\mathrm{OH}) \mathrm{D}^{(10)}$; while concentrations below $75 \mathrm{nmol} / 1(30 \mathrm{ng} / \mathrm{ml})$ determined with standardized assays have been associated with increased risk of all-cause mortality $^{(11)}$. Serum concentrations between 125 and $150 \mathrm{nmol} / 1$ (50 and $60 \mathrm{ng} / \mathrm{ml}$ ) are defined as being safe and were used to define the Tolerable Upper Intake Level (UL), based on the belief that the risk for adverse health effects rises with vitamin $\mathrm{D}$ intakes above the $\mathrm{UL}^{(22,25)}$. Vitamin D toxicity is defined as serum concentrations above $250 \mathrm{nmol} / \mathrm{l}$ $(100 \mathrm{ng} / \mathrm{ml})$ and the physiological state of vitamin D toxicity is characterized by a number of serious adverse health conditions including severe hypercalcaemia ${ }^{(26)}$.

The key to developing appropriate dietary guidelines for the prevention of vitamin D deficiency lies in the standardization of the assays used to measure $25(\mathrm{OH}) \mathrm{D}$ and the evaluation of the assay results against cut-off values for serum concentrations that correspond to well-defined vitamin D-deficient states or conditions, which may not always be specific for bone. The importance of standardizing $25(\mathrm{OH}) \mathrm{D}$ assays cannot be emphasized enough to future investigators exploring the optimal concentrations associated with reduced risk of chronic and infectious disease ${ }^{(27)}$.

Table 1 Definition of vitamin D status by 25 -hydroxyvitamin $D(25(\mathrm{OH}) \mathrm{D})$ concentration relevant to healthy populations

\begin{tabular}{|c|c|c|}
\hline $\begin{array}{l}\text { Serum } 25(\mathrm{OH}) \mathrm{D} \\
\text { concentration }\end{array}$ & Status classification & Interpretation \\
\hline $\begin{array}{l}<30 \mathrm{nmol} / \mathrm{l} \\
\quad<12 \mathrm{ng} / \mathrm{ml}\end{array}$ & $\begin{array}{l}\text { Deficiency, at risk for rickets (infants and } \\
\text { children), osteomalacia or osteoporosis }\end{array}$ & $\begin{array}{l}\text { The } 2011 \text { IOM defines vitamin D deficiency as being at risk for adverse } \\
\text { bone conditions such as rickets and osteomalacia }{ }^{(22)}\end{array}$ \\
\hline $\begin{array}{l}>50 \mathrm{nmol} / \mathrm{l} \\
>20 \mathrm{ng} / \mathrm{ml}\end{array}$ & $\begin{array}{l}\text { Sufficient, not at risk for clinical rickets, } \\
\text { osteoporosis }\end{array}$ & $\begin{array}{l}\text { The } 2011 \mathrm{IOM} \text { and other reports recommended concentrations for } \\
\text { populations to exceed for adequacy }\end{array}$ \\
\hline $\begin{array}{r}75-125 \mathrm{nmol} / \mathrm{l} \\
30-50 \mathrm{ng} / \mathrm{ml}\end{array}$ & $\begin{array}{l}\text { Optimal or vitamin } D \text { adequate for } \\
\text { non-skeletal effects of vitamin } D\end{array}$ & $\begin{array}{l}\text { Evidence of protection against chronic disease conditions exists when } \\
\text { serum concentrations are in this range. Evidence for decreased risk of } \\
\text { cancer is observed in this range, but warrant further study }{ }^{(10)}\end{array}$ \\
\hline $\begin{array}{l}125-150 \mathrm{nmol} / \mathrm{l} \\
50-60 \mathrm{ng} / \mathrm{ml}\end{array}$ & Upper Level & $\begin{array}{l}\text { Concentration set by the } 2011 \text { IOM and } 2013 \text { EFSA reports as the upper } \\
\text { safe level }\end{array}$ \\
\hline $\begin{array}{l}250 \mathrm{nmol} / \mathrm{l} \\
100 \mathrm{ng} / \mathrm{ml}\end{array}$ & Potential toxicity above this concentration & $\begin{array}{l}\text { Concentration resulting from chronic ingestion of } 250 \mu \mathrm{g}(10000 \mathrm{IU}) \text { vitamin } \\
\mathrm{D} \text {, above which adverse effects may be observed }\end{array}$ \\
\hline
\end{tabular}

IOM, Institute of Medicine; EFSA, European Food Safety Authority. 
Assay variability in the clinical determination of vitamin $D$ status and the need for standardization of analytical methods and reference materials

The common feature among all the papers in this special issue focusing on vitamin $\mathrm{D}$ is the measurement of vitamin $\mathrm{D}$ status, which is defined by the serum concentration of the intermediary metabolite of vitamin D $(25(\mathrm{OH}) \mathrm{D}, \mathrm{nmol} / \mathrm{l}$ or $\mathrm{ng} / \mathrm{ml})$. There are numerous methods for the measurement of $25(\mathrm{OH}) \mathrm{D}$ in serum ${ }^{(28-31)}$ including high-performance liquid chromatography with UV detection (HPLC/UV), liquid chromatography-tandem mass spectrometry (LC-MS/ MS) and immunoassays (radioimmunoassays (RIA), competitive protein-binding assays (CPBA), enzyme-linked immunosorbent assays (ELISA), chemiluminiscence assays (CLIA)) that are either manual or automated. LC-MS/MS (as well as HPLC) is considered the gold standard method. These two methods have the advantage that they can measure 25-hydroxycholecalciferol $\left(25(\mathrm{OH}) \mathrm{D}_{3}\right)$ and 25-hydroxyergocalciferol $\left(25(\mathrm{OH}) \mathrm{D}_{2}\right)$ separately, which is needed in specific situations. They also allow detection of other vitamin D metabolites, such as 24,25-dihydroxyvitamin $\mathrm{D}\left(24,25(\mathrm{OH})_{2} \mathrm{D}\right)^{(29,30)}$.

Formerly, all methods suffered from the lack of an international common standard; this lack contributed to the variability of results of serum $25(\mathrm{OH}) \mathrm{D}$ measurements. The Vitamin D External Quality Assessment Scheme (DEQAS) ${ }^{(30)}$ has revealed considerable differences among these methods (both within and between laboratories), raising concerns about the comparability and accuracy of different assays and laboratories ${ }^{(32-35)}$. LC-MS/MS analyses have shown that immunoassays display substantial interference of 24,25 $(\mathrm{OH})_{2} \mathrm{D}$, especially at higher $25(\mathrm{OH}) \mathrm{D}$ concentrations, giving erroneously high $25(\mathrm{OH}) \mathrm{D}$ concentrations ${ }^{(36)}$. Moreover, the 3-epi-25(OH)D metabolite, which is important in paediatric studies since the metabolite is highest during pregnancy and in infants and children, may interfere in some immunoassays ${ }^{(37)}$.

The introduction of a standard reference material for vitamin $\mathrm{D}$ in human serum by the US National Institute of Standards and Technology (NIST) ${ }^{(38)}$ has been a step forward in providing a reference measurement procedure (RMP) against which assays could be standardized ${ }^{(39)}$. The Vitamin D Standardization Program (VDSP) has developed protocols for standardizing procedures of $25(\mathrm{OH}) \mathrm{D}$ measurement in national health/nutrition surveys to promote $25(\mathrm{OH}) \mathrm{D}$ measurements that are accurate and comparable over time, location and laboratory, to improve public health practice ${ }^{(39)}$. The VDSP RMP has been joined by a number of commercial methods and laboratories that use other methods, such as DiaSorin, Liaison and Cobas, and thus their results should be comparable to LC-MS/MS with regard to $25(\mathrm{OH}) \mathrm{D}$ concentrations when the VDSP is used. In the VDSP, LC-MS/MS is the reference method. According to a reanalysis of serum $25(\mathrm{OH}) \mathrm{D}$ concentrations using the VDSP protocol, the range of mean concentrations in fourteen European studies in children and adult populations (including one study in migrants in Finland) was 38.3-65.0 nmol/1 (v. 44.8-69.0 nmol/1 in the originally analysed serum $25(\mathrm{OH}) \mathrm{D}$ data $)^{(7)}$.

\section{Examining gaps in knowledge important to public health nutrition policy and application}

The nineteen vitamin $\mathrm{D}$ research papers featured in this issue explore a number of important research gaps that are vital to our understanding of the need for food fortification or supplementation programmes in less studied low- and middle-income countries and high-risk populations in higher-income countries ${ }^{(40-58)}$. The majority of these studies examined aspects of global vitamin $\mathrm{D}$ deficiency and association with health risks ${ }^{(40,42,43,45-48,50-53,56-58)}$. Two explored the impact or need for a national vitamin D food fortification programme due to seasonal challenges or deviation from traditional diets ${ }^{(44,54)}$, while one explored the efficacy of vitamin D supplement use in a vulnerable population $^{(41)}$ and two determined the influence of season and sunlight availability year-round on vitamin D status ${ }^{(49,55)}$. Several studies used nationally representative data from higher-income countries that included different race/ ethnicity groups, allowing assessment of confounding anthropomorphic influences such as waist circumference, BMI, serum lipids and skin pigmentation ${ }^{(46,52,53)}$.

These papers bring together valued information on vitamin D status from less studied areas of the world, including Bangladesh ${ }^{(43,45)}$, China ${ }^{(42)}$, Guatemala ${ }^{(49)}$, India ${ }^{(55)}$, Iran $^{(40)}$, Malaysia ${ }^{(50)}$ and Mexico ${ }^{(56)}$. Many used state-of-theart standardized assay methodology, i.e. LC-MS/MS ${ }^{(43,47,48,54)}$, while others used EIA, RIA, CLIA ${ }^{(42,45,49-53,55-57)}$ or HPLC ${ }^{(40)}$ to analyse serum $25(\mathrm{OH}) \mathrm{D}$ concentrations, and some reported some standardization ${ }^{(47,48,53,56)}$. These differences emphasize our need to standardize the assays used to clearly understand the global extent of vitamin D deficiency and insufficiency. Such understanding can only be achieved if researchers agree to use the same clearly defined measures of serum $25(\mathrm{OH}) \mathrm{D}$ concentrations to indicate vitamin $\mathrm{D}$ deficiency, insufficiency and sufficiency, as shown in Table 1. With assay standardization and use of the same threshold values for vitamin D status, we can gain insight into global areas in need of public health nutrition policies enabling vitamin $\mathrm{D}$ food fortification and supplementation.

Mona S Calvo and Christel J Lamberg-Allardt Associate Editors

Email: christel.lamberg-allardt@helsinki.fi mscalv055@comcast.net

\section{References}

1. Grant WB, Garland HS, Gorhan ED et al. (2009) Estimated benefit of increased vitamin D status in reducing the economic burden of disease in western Europe. Prog Biophys Mol Biol 99, 104-113 
2. Hollis B (2008) Measuring 25-hydroxyvitamin D in a clinical environment: challenges and needs. Am J Clin Nutr 88, issue 2, 507S-510S.

3. Hollis B (2010) Assessment and interpretation of circulating 25-hydroxyvitamin D and 1,25-hydroxyvitamin D in the clinical environment. Endocrine Metab Clin N Am 39, 271-286.

4. Jones $G$ (2014) Interpreting vitamin $D$ assay results: proceed with caution. Clin J Am Soc Nephrol 10, 331-334.

5. Binkely N, Dawson-Hughes B, Durazo-Arvizu R et al. (2016) Vitamin D measurement standardization: the way out of chaos. J Steroid Biochem Mol Biol (Epublication ahead of print version).

6. Hilger J, Friedel A, Herr R et al. (2014) A systematic review of vitamin D status in populations worldwide. Br J Nutr 11, 23-45.

7. Cashman KD, Dowling KG, Skrabakova Z et al. (2016) Vitamin D deficiency in Europe: pandemic? Am J Clin Nutr 103, 1033-1044

8. Autier P, Boniol M, Pizot C et al. (2014) Vitamin D status and ill health: a systematic review. Lancet Diabetes Endocrinol 2, 76-89.

9. Theodoratou E, Tzoulaki I, Zgaga L et al. (2014) Vitamin D and multiple health outcomes: umbrella review of systematic reviews and meta-analyses of observational studies and randomized trials. BMJ 38, g2035.

10. McDonnell SL, Baggerly C, French CB et al. (2016) Serum 25-hydroxyvitamin D concentrations $\geq 40 \mathrm{ng} / \mathrm{ml}$ are associated with $>65 \%$ lower cancer risk: pooled analysis of randomized trial and prospective cohort study. PLOS One 11, e0152441.

11. Gaksch M, Jorde R, Grimnes G et al. (2017) Vitamin D and mortality: individual participant data meta-analysis of standardized 25-hydroxyvitamin D in 26916 individuals from the European consortium. PLoS One 12, eo17091.

12. Itkonen ST \& Lamberg-Allardt C (2016) Food fortification as a means to increase vitamin D intake. BrJ Nutr 115, 2075-2076.

13. Jääskeläinen T, Itkonen ST, Lundqvist A et al. (2017) The positive impact of general vitamin D food fortification policy on vitamin D status in a representative adult Finnish population: evidence from an 11-y follow-up based on standardized 25-hydroxyvitamin D data. Am J Clin Nutr 105, 1512-1520.

14. Babu US \& Calvo MS (2010) Modern India and the vitamin D dilemma: evidence for the need of a national food fortification program. Mol Nutr Food Res 54, 1134-1147.

15. Whiting SJ, Vatanparast H, Taylor JG et al. (2010) Barriers to the use of vitamin and mineral supplements are similar to those for healthy eating in lower income adults. Can J Diet Pract Res 71, 70-76.

16. Lhamo Y, Chugh Pk \& Tripathi CD (2016) Vitamin D in the Indian market. Indian J Pharm Sci 78, 41-47.

17. Viljakainen HT, Vaisanen M, Kemi V et al. (2009) Wintertime vitamin D supplementation inhibits seasonal variation of calcitropic hormones and maintains bone turnover in healthy men. J Bone Miner Res 24, 346-352.

18. Pittaway JK, Ahuja KD, Becket JM et al. (2013) Make vitamin $\mathrm{D}$ while the sun shines, take supplements when it doesn't: a longitudinal, observational study of older adults in Tasmania, Australia. PLoS One 8, e59063.

19. O'Neill CM, Kazantzidis A, Ryan MG et al. (2016) Seasonal changes in vitamin D - effective UVB availability in Europe and association with population serum 25-hydroxyvitamin D. Nutrients 8, 533-548.

20. Cashman KD, Kazantzidid A, Webb AR et al. (2015) An integrated predictive model of population serum 25hydroxyvitmin D for application in strategy development for vitamin D deficiency prevention. J Nutr 145, 2419-2425.

21. Sempos CT, Vespers HW, Phinney KW et al. (2012) Vitamin D status as an international issue: national surveys and the problem of standardization. Scand J Clin Lab Invest Suppl $\mathbf{2 4 3}$, 32-40.
22. Institute of Medicine, Food and Nutrition Board (2011) Dietary Reference Intakes for Calcium and Vitamin D. Washington, DC: National Academies Press.

23. Holick MF, Binkley NC, Bischoff-Ferrari HA et al. (2011) Evaluation, treatment and prevention of vitamin D deficiency. An Endocrine Society Practice Guideline. J Clin Endocrinol Metab 96, 1911-1930.

24. Newberry SJ, Chung M, Shekelle PG et al. (2014) Vitamin D and Calcium: A Systematic Review of Health Outcomes (Update). Evidence Report/Technology Assessment no. 217. Rockville, MD: Agency for Healthcare Research and Quality.

25. Scientific Advisory Committee on Nutrition (2016) Vitamin D and Health. https://www.gov.uk/government/publications/ sacn-vitamin-d-and-health-report (accessed June 2017).

26. European Food Safety Authority, Panel on Dietetic Products, Nutrition and Allergies (2013) Scientific Opinion on the Tolerable upper intake level of vitamin D. EFSA J 10, 2813.

27. Sempos CT, Durazo-Arvizu RA, Binkley N et al. (2016) Developing vitamin D assay standardization: the everpresent past. J Steroid Biochem Mol Biol 164, 115-119.

28. De La Hunty A, Wallace AM, Gibson S et al. (2010) UK Food Standards Agency Workshop Consensus report: the choice of method for measuring 25-hydroxyvitamin D to estimate vitamin D status for the UK National diet and Nutrition Survey. Br J Nutr 104, 612-619.

29. Wallace AM, Gibson S, de la Hunty A et al. (2010) Measurement of 25-hydroxyvitamin $\mathrm{D}$ in the clinical laboratory: current procedures, performance characteristics and limitations. Steroids 75, 477-488.

30. DEQAS (Vitamin D External Quality Assessment Scheme) (2015) Homepage. http://www.deqas.org/ (accessed June 2017).

31. Carter CD (2012) 25-hydroxyvitamin D: a difficult analyte. Clin Chem 58, 486-488.

32. Snellman G, Melhus H, Gedebourg R et al. (2010) Determining vitamin D status: a comparison between commercially available assays. PLoS One 5, e11555.

33. Carter GD (2011) Accuracy of 25-hydroxyvitamin D assays: confronting the issues. Curr Drug Targets 12, 19-28.

34. Farrell CJ, Martin S, McWhinney B et al. (2012) State-of-the-art vitamin D assays: a comparison of automated immunoassays with liquid chromatography-tandem mass spectrometry methods. Clin Chem 58, 531-542.

35. Heijboer A, Blankenstein M, Kema IP et al. (2012) Routine 25-hydroxyvitamin D assays influence vitamin D binding protein concentrations. Clin Chem 58, 543-548.

36. Cashman KD, Hayes A, Galvin K et al. (2015) Significance of serum 24,25-dihydroxyvitamin $\mathrm{D}$ in the assessment of vitamin D status: a double-edged sword. Clin Chem 61, 636-645.

37. Baily D, Perumal N, Yazdanpanah M et al. (2014) Maternalfetal dynamics of the c3-epimer of 25-hydroxyvitamin D. Clin Biochem 47, 816-822.

38. National Institute of Standards and Technology (2010) NIST SRM 2972 25-Hydroxyvitamin $D_{2}$ and $D_{3}$ Calibration Solutions. In SRM Spotlight, March 2010, p. 4. http://www. nist.gov/srm/upload/march-2010-Spotlight-3.pdf (accessed June 2017).

39. Cashman KD, Kiely M, Kinsella M et al. (2013) Evaluation of vitamin D standardization program protocols for standardizing serum 25-hydroxyvitamin D data: a case study of the program's potential for national nutrition and health surveys. Am J Clin Nutr 97, 1235-1242.

40. Saki F, Dabbaghmanesh MH \& Omrani GR (2017) Vitamin D deficiency and its associated risk factors in children and adolescents in southern Iran. Public Health Nutr 20, 1851-1856.

41. McCormack D, Mai X \& Chen Y (2017) Determinants of vitamin D supplement use in Canadians. Public Health Nutr 20, 1768-1774. 
42. Yun C, Chen J, He Y et al. (2017) Vitamin D deficiency prevalence and risk factors among pregnant Chinese women. Public Health Nutr 20, 1746-1754.

43. Perumal N, Mahmud AA, Baqui AH et al. (2017) Prenatal vitamin D supplementation and infant vitamin D status in Bangladesh. Public Health Nutr 20, 1865-1873.

44. Sandmann A, Amling M, Barvencik F et al. (2017) Economic evaluation of vitamin D and calcium food fortification for fracture prevention in Germany. Public Health Nutr 20 , 1874-1883.

45. Ahmed AMS, Ahmed T, Long KZ et al. (2017) Prevalence and risk factors of vitamin D insufficiency and deficiency among 6-24-month-old underweight and normal weight children living in an urban slum of Bangladesh. Public Health Nutr 20, 1718-1728.

46. Rajan S, Weishaar T \& Keller B (2017) Weight and skin colour as predictors of vitamin D status: results of an epidemiological investigation using nationally representative data. Public Health Nutr 20, 1857-1864.

47. Djekic-Ivankovic M, Weiler H, Jones G et al. (2017) Vitamin D status in mothers with pre-eclampsia and their infants: a case-control study from Serbia, a country without a vitamin D fortification policy. Public Health Nutr 20, 1825-1835.

48. Heath AK, Williamson EJ, Kvaskoff D et al. (2017) 25 Hydroxyvitamin D concentration and all-cause mortality: the Melbourne Collaborative Cohort Study. Public Health Nutr 20, 1775-1784.

49. Naqvi A, Solomons NW, Campos R et al. (2017) Vitamin D status among indigenous Mayan (Kekchi) and Afro-Caribe (Garifuna) adolescents from Guatemala: A comparative description between two ethnic groups residing on the Rio Dulce at the Caribbean Coast in Izabal Province, Guatemala. Public Health Nutr 20, 1729-1737.

50. Moy FM, Hoe VCW, Hairi NN et al. (2017) Vitamin D deficiency and depression among women from an urban community in a tropical country. Public Health Nutr 20, 1844-1850.

51. Pannu PK, Zhao Y, Soares MJ et al. (2017) The associations of vitamin D status and dietary calcium with the metabolic syndrome: an analysis of the Victorian Health Monitor survey. Public Health Nutr 20, 1785-1796.

52. Lee S-H, Suh E, Park K-C et al. (2017) Association of serum 25hydroxyvitamin D and total serum cholesterol with depressive symptoms in Korean adults: The Fifth Korean National Health and Nutrition Examination Survey (KNHANES V, 2010-2012). Public Health Nutr 20, 1836-1843.

53. Vogt S, Baumert J, Peter A et al. (2017) Effect of waist circumference on the association between serum 25hydroxyvitamin D and serum lipids: results from the National Health and Nutrition Examination Survey 2001-2006. Public Health Nutr 20, 1797-1806.

54. O'Brien DM, Thummel KE, Bulkow LR et al. (2017) Declines in traditional marine food intake and vitamin D levels from the 1960 s to present in young Alaska Native women. Public Health Nutr 20, 1738-1745.

55. Sudhanshu S, Upadhyay P, Sahu M et al. (2017) Sun exposure, UV irradiance and serum 25-hydroxycholecalciferol in pregnant women in rural north India. Public Health Nutr 20, 1755-1759.

56. Flores A, Flores M, Macias N et al. (2017) Vitamin D deficiency is common and is associated with overweight in Mexican children aged 1-11 years. Public Health Nutr 20, 1807-1815.

57. Omand JA, To T, O'Connor DL et al. (2017) 25-Hydroxyvitamin D supplementation and health service utilization for upper respiratory tract infection in young children. Public Health Nutr 20, 1816-1824.

58. Holland A \& Moffat T (2017) Comparing measured calcium and vitamin D intakes with perceptions of intake in Canadian young adults: insights for designing osteoporosis prevention education. Public Health Nutr 20, 1760-1767. 